\title{
This Is, and Is Not, Shakespeare: A Japanese-Korean Transformation of Othello
}

\author{
Emi Hamana \\ University of Tsukuba \\ emihaman@sakura.cc.tsukuba.ac.jp
}

\begin{abstract}
The purpose of this paper is to address the critical impact of local Shakespeare on global Shakespeare by examining a Japanese-Korean adaptation of Othello. Incorporating elements of Korean shamanistic ritual and elements from Japanese noh to create a new reading of Shakespeare's play with its special concern with Desdemona's soul, the two theatres interact powerfully with each other. Local Shakespeare functions as a cultural catalyst for the two nations vexed with historical problems. By translating and relocating Shakespeare's Othello in East Asia, the adaptation succeeds in recreating Shakespeare's play for contemporary local audiences. In considering the adaptation, this paper explores the vital importance of local Shakespeare and local knowledge for the sake of global Shakespeare as a critical potential. The adaptation might evoke a divided response among a non-local audience. While on the one hand, it attempts to create an 'original' production of the Shakespeare play through employing the two Asian cultures, on the other, it employs the Shakespeare play as a conduit for their cultural exchange. This is, and is not, Shakespeare. The paper finally suggests that for all this ambivalence, the adaptation shows some respectful, if unfamiliar, feelings that could be shared by many people around the globe.
\end{abstract}

\section{Introduction}

Globalisation has led to localisation and identity politics. The linkage between the global and the local has, however, been contradiction-ridden because of cultural 
production that produces uneven cultural capital (Wilson and Dissanayake, 1996: 5). If we hope to survive this late-capitalist system and postmodern ambivalence, in all probability, we shall have to aspire to transnational or cosmopolitan solidarity, an unfulfilled dream as it might seem, as Bauman (1993: 234-38) propounds, and as, indeed, while emphasising Shakespeare's hospitality towards strangers, Richard Wilson (2007: 242-60) also suggests. The question of global Shakespeare will entail that of local Shakespeare and, furthermore, that of 'glocal' Shakespeare. For centuries, Shakespeare's works have been read in English, translated into an enormous diversity of languages, adapted and performed in a plethora of styles, local or otherwise. Through this process of global spread, Shakespeare has been naturalised, localised and even indigenised to such an extent that some non-English cultures regard him as their home author. No matter what we might call this phenomenon - whether localisation, acculturation or cultural articulation - we find a collapse of the global and the local into the glocal.

The fundamental point of the apparently confusing tripartite question of global/local/glocal is, however, that whether or not our location is metropolitan, most of us are ambivalent about global Shakespeare. While, on the one hand, we have great expectations of it, on the other, most of us have equally great anxiety about it. We tend to notice prominent postcolonial resistance against global Shakespeare or anger about uneven relations or exchange between the metropolis and others, the West and the rest. Yet metropolitan academics no longer seem to feel quite secure themselves. For example, the fourth British Shakespeare Association Conference was held in London in September 2009 under the theme 'Local/Global Shakespeares'. There, a leading British Shakespeare scholar, who co-authored one edition of Shakespeare's Sonnets, declared, with tongue in cheek, that since the theme of the conference was local/global Shakespeare, he would like to present a local version, and read, with his co-author, sonnets in English with hilarious and incisive comments. Here we could detect the perennial British or metropolitan predilection for a good sense of humour and sarcasm, and at the same time, a counter-resistance against the force of ascribing any nation and culture (among others, English, the very nation and culture that produced the greatest dramatist in the world) a local status. In the British scholar's discourse, however, we can also find a symptom of the metropolitan anxiety about the uncertain consequences of the spread of global Shakespeare as well as the anxiety about English cultural and linguistic identity, if not hegemony.

English Shakespeare today is now as much a global as a national phenomenon, and both his language and thematic resources can be exploited in multiple ways, at once from the inside -to give just a few examples, Shakespeare's play in a Scottish accent and a variety of popular or subcultural Shakespeare videos on YouTube as a kind of intracultural performance in the UK- and from the outside, as directors, performers and audiences triangulate among the local, global and personal landscapes of their worlds. ${ }^{1}$ Compared with the old global Shakespeare in previous centuries spread by British colonial rule and internationalism (Dionne and Kapadia, 2008: 5) notice a new 'global Shakespeare' in recent years — produced by the economic globalisation led by the USA, 
the rise of (American) English as a global language and new media technology — with critical reservations:

There has been, in the last 10 years, an explosion of critical interest in the way Shakespeare has been made to accommodate local cultures across the globe, a critical trend that works concurrently and in concert with the global English-speaking media aspiring to shape Shakespeare as an international artist. A new progressive internationalism has slowly and — some would say 'at long last' — reshaped the academic discourses of intellectual labor in the profession of English in the United States, creating the opportunity for truly multiregional conferences and festivals to address a new 'global Shakespeare'.

Resisting this new global Shakespeare and discourse, Dionne and Kapadia (2008: 7) focus on "the persistent indigenization of Shakespeare" and intend to make Shakespeare "a site of contest." Suspecting the global reach of the metropolitan knowledge of Shakespeare and texts at the expense of ever-existing inequality between metropolitan discursive practice and its non-metropolitan counterpart, however, Orkin (2005: 2) writes:

Without denying the simultaneous indispensability of the already existing shared achievements and knowledges of metropolitan Shakespeare scholarship, I want to argue that the kinds of knowledge that, especially, particularly non-metropolitan locations whether they are located within twenty-first-century Europe and North America but outside the Shakespeare metropolitan academy, or beyond it - might afford, may themselves, in turn, offer additional opportunities for thinking about Shakespeare's plays.

In accord with his argument, the present paper tries to contribute to reforming contemporary global Shakespeare through examining a local performance. It is possibly preferable for us to seek more positive glocalisation as an integration of globalisation and localisation than a collapse of the global and the local into the glocal as a phenomenon, beyond a fixed binary opposition between the global and the local. Reception and transformation specialists in non-English-speaking countries in particular are more acutely concerned with the impact of local Shakespeare on global Shakespeare. We aim to explore its critical potential to question contemporary global Shakespeare and accommodate a multiplicity of positions and diversity of voices towards the horizon of integrated glocal Shakespeare. The purpose of this paper is to address the issue of global Shakespeare mainly by examining a Japanese-Korean adaptation of Othello, but it will also deal with related topics such as translation, adaptation and intercultural performance. 


\section{Othello in the Japanese mugen noh style with elements of Korean shamanism: a creative subversion}

Japan has performed Shakespeare plays since the nineteenth century and has more recently been home to internationally acclaimed directors such as Tadashi Suzuki and Yukio Ninagawa. Korea started to perform Shakespeare plays late, but their performances — and, in particular, their adaptations - are very popular today under distinguished directors such as Oh Tae-suk and Lee Yun-taek (Lee, 2008: 1-4). ${ }^{3}$ Both countries have performed adaptations from Shakespeare in a variety of styles Western, traditional and experimental - and, furthermore, have conducted regular theatre exchanges since the early 1990s.

In 2005, Ku Na'uka performed Othello in Noh Style, an adaptation by Sukehiro Hirakawa of Shakespeare's Othello in noh form. Lee Youn-taek, a leading Korean director who had been familiar with Miyagi's work for many years, was asked to direct Othello in Noh Style as 'a Japanese-Korean collaboration'. This collaboration, performed in Seoul in 2008 and at Festival/Tokyo in Tokyo in 2009, was seen as highly creative and transformative because of the synergy of the two experimental theatre companies and their styles. The performance incorporated elements of Korean shamanistic ritual and dance (the Chohongut) and elements from Japanese noh to create a new reading of Shakespeare's Othello, for "[I]t is usually at the very point of infidelity that the most creative acts of adaptation and appropriation take place." Sanders (2006: 20).

Before looking at the Japanese-Korean collaboration, it is crucial to discuss $\mathrm{Ku}$ Na'uka's Othello in Noh Style, directed by Miyagi. In Shakespeare's Othello, a Moor and a Venetian lady fall in love despite their age/racial differences. However, their love is the trigger that prompts a tragedy of jealousy and revenge. At the request of Miyagi, Hirakawa adapted this beautiful and cruel tragedy into a mugen [dream] noh script. In his rewriting of the famous play, the ghost of Desdemona, who is killed by Othello, lives on in the memory of her husband. Othello in Noh Style departs radically from the original tragedy, which follows Othello's descent into violent jealousy; instead, the noh interpretation attempts to represent a world of yugen - the noh concept of profound and refined beauty that Zeami adapted from Japanese traditional aesthetics and made into a theatrical ideal. Othello in Noh Style is a story of the paradox of love and hatred between man and woman. The moment when Desdemona is murdered by her husband remains the most vital moment in her life, the moment that allows her ghost to continue to exist. Some might regard the pathos in this narrative thread as overwhelming, but this is precisely the central theme of this production. This rereading of Othello attempts to show that hope can emerge even within the broken marriage of Othello and Desdemona. Desdemona's passionate hope re-emerges despite everything, and this prompts an emotionally moving reaction among the audience. In Miyagi's view, noh has a function that modern theatre does not have; it is a drama performed to relieve human loneliness. It presents the dynamic journey from the extreme of loneliness to the extreme of relief. 
$\mathrm{Ku}$ Na'uka's Othello in Noh Style is no longer a Western tragedy, but is instead transformed into a communal tragedy. Miyagi suggests that when Shakespeare's Othello is performed in noh style, the darkness or hopelessness in the original is alleviated in some way. In the original play, it has long been recognised that it is extremely difficult to identify a sense of catharsis. Othello in Noh Style is the Japanese director's attempt to address this hopelessness by casting the tale in mugen noh style, fusing Western and Eastern culture and eventually providing a communal resolution to modern loneliness.

This cultural fusion allows Shakespeare's play to be reinterpreted anew. It allows the audience into the dimension of Desdemona's mind. Inspired by noh style, Miyagi subverts Shakespeare's tragedy in a creative way, transforming it into a soul-consoling artistic work. Furthermore, Miyagi's re-interpretation or betrayal of the concept of Western tragedy is, in fact, a creative one that produces a highly original intercultural performance of a Shakespeare play with rich implications and spiritual depth.

In 2008, Othello in Noh Style was performed, under Lee's direction, with the collaboration of the leading members of Miyagi's company and two members of Lee's theatre company. This production breathed new life into Shakespeare's Othello. Miyagi proposed the idea of Othello in mugen noh style while he explored the strength of Japanese theatre. By using Korean shamanistic dance (the Chohongut) as a style with which to interpret Othello, Lee added elements of Korean shamanism to his interpretation and used a recognisable form of dialogues with a spirit, adopting the Korean ritualistic drama of gut. In his fused version, Lee used noh to represent the world of the dead and deities; it is a dream or imaginary world. The traditional Korean shamanism then allowed a shaman to conduct dialogues with the dead, those with spirits. By combing noh style with gut in his production, Lee hoped that the idealistic elements of both the Japanese and Korean cultures could form a fused ideal world in Othello.

While directing Othello in Noh Style for the new collaborative Japanese-Korean production, Lee noticed the common threads that ran through both Korean shamanistic ritual (the Chohongut) and a mugen noh style and tried to fuse these traditions through classic English drama. Scenes from Shakespeare's original play are performed in the two interludes, but the locations for the main events of the Japanese-Korean collaboration are transferred from Venice to the peninsula and from Cyprus to the southern island, while the style shifts between the mugen noh and the Chohongut.

The Japanese-Korean version of Othello is set two thousand years ago and is located on an island in ancient Asia, where a sad and cruel story of love between a woman of the peninsula and a man of the Southern sea is developed. Desdemona is a person from overseas (i.e., from the Korean Peninsula), and Othello is a dark southerner and a man of the sea (i.e., a man of Okinawa); East Asia becomes the location of the action instead of the Mediterranean Sea in Shakespeare's original. The Japanese-Korean collaboration superimposes the ancient history of East Asia onto the story of Early Modern Europe; in this version, the tale is more multi-layered and complex, and these changes can be considered to have expanded the play on an epic scale by increasing the cultural 
complexity and dynamism as well as widening the focus. Furthermore, Lee adopts a directional strategy that does not aim to emulate Western text-based realism; instead, he employs an Asian style, focusing on visuality, physicality and musicality.

The ending of Lee's Othello differs both from Shakespeare's original play and from Miyagi's mugen noh version, in that it involves a Korean theatrical parade with musicians coming onto the stage immediately before the ending of the play. Indeed, Othello and Desdemona appear hand in hand, walking alongside other characters! In addition, the violent ending of Shakespeare's tragedy is modified in both versions. In the mugen noh version, the gruesome ending is displaced by a quiet and peaceful ending; in the Chohongut version, it is transformed into a festive comedy. Both Asian versions transform the darkness of the original ending into a lighter finale. The lively ending of Lee's version is unimaginable in both Shakespeare's tragedy and the noh play. In the noh version, all of the actors, musicians and singers exit in silence; they leave the stage empty in an attempt to allow the audience to empty and purify their own minds.

When he discusses the difference between the mugen noh version and the Chohongut version, Lee suggests that ideally, no tragedy should exist in Korea, since pain and grief is released by spirits and living people communally in Korean culture. At the end of Othello in Noh Style, the audience feels a sense of catharsis or purification; at the ending of Lee's Othello, the audience is distracted from the horrible tragedy and is soon engrossed in the sense of play that infuses the next scene, which focuses on the shamanistic and festive atmosphere of song and dance.

Miyagi felt that a Japanese audience would not feel purified by watching Shakespeare's Othello in its original form, and he asked Hirakawa to adapt it into a noh version. As has previously been made clear, the noh version transformed the Western tragedy into a hybrid play, with both Western and Eastern elements.

For Lee, the priority in creating an intercultural performance is to encourage exchange and negotiations among Asian theatres; with this in mind, it seems likely that he is attempting to betray the concept of Western tragedy. Lee's Othello does significantly transform Shakespeare's tragedy; nonetheless, the transformation is a theatrical pleasure for most local audiences. The Korean director committed a creative subversion of Miyagi's premises; he boldly created a play that went beyond Miyagi's expectations. Shakespeare's tragedy is transplanted into another culture in ancient East Asia, and the tragedy becomes transformed through noh and the Chohongut into an alternative theatrical experience in which the audience finds a sense of relief and joy.

Shakespeare's great tragedies, such as Othello, do contain fundamental problems of human existence such as evil, death and suffering. Unlike other familiar tragic productions that end with the catastrophic death of the main characters on the stage, this intercultural production of Othello goes further. Rather than limiting itself to only representing death and suffering, the Japanese-Korean adaptation of Othello also explores notions of relief. Inspired, on the one hand, by the mugen noh tendency to see the world from the perspective of the dead and, on the other, the Korean shamanism that connects this world with the other world, the intercultural performance extends the 
notions of grief and suffering to include explorations of release. This suggests that this new reading of Othello can be regarded as a creative subversion.

\section{Translation issues}

Sukehiro Hirakawa, a distinguished Japanese scholar of comparative literature and polyglot, adapted Shakespeare's Othello, whichever English and Japanese text(s) he might have consulted, to a noh script. When he directed it, Miyagi added several interludes in which scenes from the original text were performed. He used a Japanese translation by Yūshi Odashima, whose translations of the complete works of Shakespeare -37 plays - were published between 1973 and 1980. Odashima's translation is famous for its taste for wordplay and speed, and for making Shakespeare plays seem as if they are contemporary plays in Japanese. ${ }^{4}$ Both Othello in Noh Style, directed by Miyagi, and the Japanese-Korean collaboration, directed by Lee, are, however, characterised more by their adaptations than by their translations. This section, therefore, will confirm several aspects of translation as a prerequisite to adaptation.

In the first place, responding to Walter Benjamin's famous essay in "The Task of the Translator," Derrida (2007: 207), who had a long-standing interest in the question of translation, writes about the primal importance of translation:

Nothing is more serious than a translation. I rather wished to mark the fact that every translator is in a position to speak about translation, in a place that is certainly not second or secondary. For if the structure of the original is marked by the requirement to be translated, it is because in laying down the law, the original begins by indebting itself as well with regard to the translator. The original is the first debtor, the first petitioner; it begins by lacking — and by pleading for translation.

Furthermore, Derrida (2007: 211) writes:

If the translator neither restitutes nor copies an original, it is because the original lives on and transforms itself. In truth, the translation will be a moment in the growth of the original, which will complete itself in enlarging itself.

Although he does not say that any translation will do, Derrida's thoughts are highly insightful with regard to the position that the original demands translation because of its primary lack and that the translation will complement it, contributing to its growth. This complementary or symbiotic relationship between the original and the translation is suggestive as regards the reconsideration of local/global Shakespeare. It is very likely that global Shakespeare demands local Shakespeare.

There has been real development in the translation studies of Shakespeare. In Shakespeare and the Language of Translation, among others, the editor, Hoenselaars (2004: 1-27; 2009), attempts to reveal that meaning is not permanently rooted in the 
original text of Shakespeare but is, to a large extent, determined by the context, and we come to realise that every new translation makes Shakespeare 'more contemporary'. This means not only that translation makes Shakespeare's early modern English more contemporary and accessible in each location, but also that by making Shakespeare more contemporary, translation makes Shakespeare more meaningful and interesting for the contemporary audience and reader. Most of Shakespeare's plays were contemporary to the initial audience in early seventeenth-century London. It is quite sensible to attempt to make Shakespeare's texts more contemporary today in order to reconstruct the initial relationship between text and audience.

\section{4 . Intercultural adaptation issues}

Since the Japanese-Korean collaboration of Othello is an intercultural adaptation, both interculturalism and adaptation will be discussed here. Interculturalism has been a controversial topic in theatre studies, since it presents theoretical and practical difficulties, problems and even dangers, ranging from excessive desire for others to the increasing complexity of contemporary cultural exchange, transformation and hybridisation. As is well known, interculturalism derives itself from Orientalism, which still overshadows its development:

Interculturalism is a means of imagining culture as a landscape which, when occupied, produces, transmits, and substitutes for a once authentic culture. Rather than a mutual meeting in a space between cultures, intercultural performance is most often a practice of the desire, imagination and anxieties of the one cultural system that looks to the other culture for formalist or aesthetic templates for the renovation of itself. Intercultural theatre thus operates in the space between two or more cultures, but those cultures themselves rarely, if ever, meet, let alone interact. (Kennedy, 2003: Vol.1, 630) ${ }^{5}$

Discussing Shakespearean geographies, Worthen (2003: 130) writes that "European intercultural performance is firmly conjoined to the history of imperial expansion," and further that "the globalized economy is the condition of intercultural performance today." "A new form of interculturalism" (Singleton, 2009: 195) is, therefore, expected to replace the existing version, Western or not. ${ }^{7}$ In her Adaptation and Appropriation, Sanders (2006: 9) writes:

....adaptation could be defined as an inherently conservative genre.... Yet, as the notion of hostile takeover present in a term such as 'appropriation' implies, adaptation can also be oppositional, even subversive. There are as many opportunities for divergence as adherence, for assault as well as homage.

In this intercultural adaptation, Japanese theatre and Korean theatre powerfully interact with each other. Local Shakespeare functions as a cultural catalyst for the two nations that have been vexed with historical problems, at the risk of being appropriated 
by the global Shakespeare industry. By translating and relocating Shakespeare's Othello in East Asia, and adapting and subverting the Orientalism that is apparently inherent in the original text, the Japanese-Korean adaptation of Othello succeeds in recreating Shakespeare's play for contemporary local audiences.

Miyagi believes that those involved in theatre must deal both with Western drama classical and modern- and Japanese classical drama. He is also very concerned with 'the pan-East-Asian' identity in all its manifestations, an identity that he regards as ever in flux. From performing in India, Korea, China and Tibet, Miyagi has become aware of the perennial interaction that has been occurring between Asian cultures and the exchange that informs the various senses of beauty throughout the region. For this reason, he now finds it meaningless to differentiate between an original theatre work and a so-called copy in Asia, despite the fact that there seem to be significant differences between the types of regional theatre. Miyagi prioritises cultural commensurability in all his work, especially what he sees as a pan-East-Asian commonality and a common Asian cultural connection, and pursues an intercultural or transcultural performance. In the current critical and theoretical climate, however, this notion of a common cross-cultural theatrical form might be criticised for homogenising the diverse cultural and theatrical forms and traditions by assimilating them all into a single pan-East-Asian framework.

While a plethora of Shakespeare productions, theatre histories and forms have been produced throughout the world, the research that has been conducted on them has been extremely disjointed and fragmented. This lack of a unified overview of the global interpretations of Shakespeare reflects, in part, their dazzling complexity and dynamism. Confronted with the ever-increasing linguistic, cultural and interpretative diversity of Shakespearean productions, most Shakespeare scholars in this age of cultural pluralism and post-colonialism avow that diversity. However, no holistic paradigm of intercultural Shakespeare productions has yet been established. If we bear in mind the cultural value differences that exist among diverse cultures without essentialising them, then it is clear that Miyagi's general view may well be significant in attempting to outline this holistic paradigm of great significance.

By combining noh style with gut in his production, Lee hopes that the idealistic elements of both the Japanese and Korean cultures can form a fused ideal world in Othello. However, Lee was aware of the potential perils of this method. Any production that combined Shakespeare's original play with both Japanese noh style and Korean shamanism could easily become a sheer spectacle. Despite this danger, he regarded the project as worthwhile and rewarding. Lee (2008: author's translation) believed that this fusion of styles was valid, since "[W]estern theatre originates in the Dionysian festival"; this is also the case for Japanese and Korean theatre, both of which originate in ritualistic festivals. Lee concludes his interview as follows:

After all, the world is one. I believe that all people have the same feeling about rituals. Whether Shakespearean drama, Japanese tradition, gut or shamanism, they all originate at 
the same source, and therefore, there must be a way for them to communicate with each other. The task of finding this way will be difficult, but I think it will be fun.

Festival/Tokyo is held not only to showcase conventional and popular works as a kind of cultural tourism, but also to expose people to works with which they may be unfamiliar, works that demonstrate new artistic expressions and values. The members of the executive committee of the festival are keen to ensure that the festival remains avant-garde and provocative, and challenges the artistic mainstream, local and global. Against this wider framework of the festival, it is clear that Lee's firm belief in international cultural exchange reflects the values of the festival well and offers a significant challenge to the contemporary theatre scene. More importantly, his belief and practice contribute to reforming global Shakespeare.

The Japanese-Korean adaptation of Othello has several features as described in 2-1, of which the most striking is its great concern with Desdemona's soul. In the Japanese noh version, directed by Miyagi, the main focus is on her salvation, as it is in the Japanese-Korean adaptation, directed by Lee. Shakespeare's text is open to a variety of readings, as it contains a medley of ideas about life and death, Christian or nonChristian. Having said this, Shakespeare criticism is mainly concerned with the racial issue of Othello as a foreigner. It is uncertain why the majority of audiences and theatre people seem to care very little about Desdemona's well-being after her death. It might be attributed to Othello's speech, which suggests, in his mind, her salvation: "When we shall meet at compt/This look of thine will hurl my soul from heaven/And fiends will snatch at it" (5.2.273-5).

Among the many adaptations of Othello in the world, the feminist adaptation, or rather appropriation, has been most noteworthy since the late twentieth century (e.g., Paula Vogel's Desdemona: A Play about a Handkerchief (1993)). Vogel transforms Shakespeare's heroine into a sexually liberated woman. She could be said to have 'saved' Desdemona from the status of a passive victim, endowing her with agency. Yet Vogel has no concern with Desdemona's spiritual condition after her death.

Although the present writer's research is limited, it is in all probability correct to say that the Japanese-Korean adaptation's concern with Desdemona's salvation is unique. As some members of the Japanese audience felt uncomfortable about Lee's festive ending, not all people can appreciate it, finding it a transgression from the original. Whether or not the audience or readers can appreciate it, it is evident that the most creative act of adaptation takes place at the very point of infidelity.

In fact, the Japanese-Korean adaptation sheds light on Shakespeare's unique culture. In Christian tradition, each individual's salvation or damnation will be judged finally by God. In Japanese-Korean traditions (influenced by Buddhism, Taoism, Shinto, shamanism, etc.), what matters most is not each individual's salvation but collective salvation through a communal ritual. This local Shakespeare has a critical impact on global Shakespeare through its cross-cultural questioning, reception and transformation or creative subversion. The ending of the Japanese-Korean adaptation is thoughtprovoking, since the uniqueness of Shakespeare's original text, its cultural context, as well as its Christian tradition is disclosed, questioned and subverted. 


\section{Conclusion}

In considering the Japanese-Korean adaptation of Othello, this paper has explored the vital importance of local Shakespeare and local knowledge for the sake of global Shakespeare as a critical potential. The adaptation might evoke a divided response among a non-local audience. While on the one hand, it attempts to create an 'original' production of the Shakespeare play through employing the two Asian cultures, on the other, it uses the Shakespeare play as a conduit for their cultural exchange. This is, and is not, Shakespeare. Yet this ambivalence is not all. The adaptation shows some respectful, if unfamiliar, feelings that could be shared by many people around the globe. Despite all possible difficulties and challenges, we should certainly head for the goal of a new global Shakespeare. Shakespeare is always in a state of flux, crossing boundaries, moving to other locations, negotiating, changing, and transforming performers and audiences.

\section{Notes}

1. There seems to be an affinity between global Shakespeare and world literature. Damrosch (2003: 230) writes: "English Literature is now as much a global as a national phenomenon, and both its language and its thematic resources can be multiply exploited, at once from inside and from outside, as writers triangulate among the local, the international, and the personal landscapes of their worlds."

2. A linguistic problem should be noted. Global Shakespeare facilitates local Shakespeares. Yet it is hard for non-locals to understand and discuss them, unless they are performed in English as a global language or with English subtitles.

3. A useful chronology of "Shakespeare in Hollywood, Asia and Cyberspace" is provided in Huang (2009: 265-74).

4. In his recent book, Kenji Ōba, who is an editor of ten Shakespeare plays and has been translating all of his plays in 'verse', questions all of his predecessors, including Odashima and Kazuko Matsuoka, in that they employed English editions of Shakespeare's texts without editing them themselves and without knowing much about the advancement of textual studies. Although his poignant criticism and practice are of great merit, Ōba's verse translation based on his neo-classicalism runs the risk of again turning Shakespeare's plays into antiquated closet drama.

5. See also Bennett, 1997: 166-203; Bharucha, 2000: 3-6; Shepherd and Wallis, 2004: 198206; Hodgdon, 2005: 158-59; Zarrilli, 2006: 108-133; Yong, 2007: 527-49)

6. Singleton (2009: 196-97) examines two Korean productions of Shakespeare plays that were performed at the Barbican Centre in London in 2006: Mokwha Theatre Company's Romeo and Juliet, directed by Oh Tae-suk, and Yohangza Theatre Company's A Midsummer Night's Dream, directed by Yang Jung-ung. Singleton concludes: "What we were witnessing then in London was glocalisation of an international brand (i.e., Shakespeare) in performance. This is hugely significant for the future of the intercultural, as it is intracultural experience that challenges national ownership of any culture, Asian or European. ...these productions manifest a 'pursuit of otherness for the investigation of self' ... That self can be national or international, 
local or global, and is a self that is redolent of a desire for casting an eye intraculturally to heritage, pastness and ancient tradition to illuminate the contemporary experience of being in the world."

\section{References}

Bauman, Zygmunt (1993): Modernity and Ambivalence. Oxford: Polity Press.

Bennett, Susan (1997): Theatre Audiences: A Theory of Production and Reception. Second ed. London: Routledge.

Bharucha, Rustom (2000): The Politics of Cultural Practice: Thinking Through Theatre in an Age of Globalization. London: The Athlone Press.

Damrosch, David (2003): What Is World Literature? Princeton: Princeton University Press.

Derrida, Jacques (2007): "Des tours de Babel." In Peggy Kamuf and Elizabeth Rottenberg, eds., Psyche: Inventions of the Other, Vol.1. Stanford: Stanford University Press, 191-225.

Dionne,Craig and Parmita Kapadia, eds. (2008): Native Shakespeares: Indigenous Appropriations on a Global Stage. Oxford: Ashgate.

_ (2011): "Othello in the Japanese mugen noh style with elements of Korean shamanism." Studies in Literature and Linguistics (Tsukuba University) 59: 75-91.

Hodgdon, Barbara (2005): “Afterword: Do dead playwrights have rights?" In S. Massai, ed., World-Wide Shakespeares: Local Appropriations in Film and Performance. London: Routledge, 158-59.

Hoenselaars, Ton, ed. (2004): Shakespeare and the Language of Translation. London: Thomson Learning.

- (2009): "Translation futures: Shakespearians and the foreign text." In Peter Holland, ed., Shakespeare Survey 62: Close Encounters with Shakespeare's Text. Cambridge: Cambridge University Press, 273-82.

Huang, Alexander C. Y. (2009): Chinese Shakespeares: Two Centuries of Cultural Exchange. New York: Colombia University Press.

Kennedy, Dennis, ed. (2003): The Oxford Encyclopedia of Theatre and Performance. 2 vols. Oxford: Oxford University Press.

Lee, Hyon-u et al., eds. (2009): Glocalizing Shakespeare in Korea and Beyond. Seoul: Dongin Publishing.

Lee,Youn-taek, dir. (2008): Othello. Interview, 30 September 2008, http://festivaltokyo.jp/09sp/press/Othello-pdf, 5 December 2010. Online.

Ōba, Kenji (2009): Shakespeare no Honyaku (Japanese Translations of Shakespeare). Tokyo: Kenkyusha.

Orkin, Martin (2005): Local Shakespeares: Proximations and Power. London: Routledge.

Sanders, Julie (2006): Adaptation and Appropriation. London and New York: Routledge.

Shepherd, Simon and Mick Wallis (2004): Drama/Theatre/Performance. London: Routledge.

Singleton, Brian (2009): "Intercultural Shakespeare from intracultural sources: Two Korean performances." In Lee Hyon-u et. Al., Globalizing Shakespeare in Korea and Beyond. Seoul: Dongin Publishing, 179-98.

Vogel, Paula (2000): "Desdemona: A play about a handkerchief." In D. Fischlin and M. Fortier, eds., Adaptations of Shakespeare: A Critical Anthology of Plays from the Seventeenth Century to the Present. New York: Routledge, 233-54. 
Wilson, Richard (2007): Shakespeare in French Theory: King of Shadows. New York: Routledge.

Wilson, Rob and Wimal Dissanayake, eds. (1996): Global/Local: Cultural Production and the Transnational Imaginary. Durham and London: Duke University Press.

Worthen, W. B. (2003): Shakespeare and the Force of Modern Performance. Cambridge: Cambridge University Press.

Yong, Li Lan (2007): "Shakespeare and the fiction of the intercultural." In Barbara Hodgdon and W. B. Worthen, eds., A Companion to Shakespeare and Performance. Oxford: Blackwell, 527-49.

Zarrilli, Phillip B (2006): "For whom is the king a king? Issues of intercultural production, perception, and reception in a Kathakali King Lear." In Janelle G. Reinelt and Joseph R. Roach, eds., Critical Theory and Performance. Ann Arbor: University of Michigan P, 108133. 